\title{
"Discutir educação é discutir trabalho docente": o trabalho docente segundo dirigentes da Confederación de Trabajadores de la Educación de la República Argentina (CTERA)*
}

\author{
Márcia Ondina Vieira Ferreira \\ Universidade Federal de Pelotas, Faculdade de Educação
}

Introdução: objetivos e metodologia do estudo

Este artigo apresenta recorte de uma pesquisa cujo objetivo principal foi examinar as conexões entre sindicalização e percepção do trabalho docente como profissional ou proletarizado, segundo uma central latino-americana de trabalhadores em educação, a Confederación de Trabajadores de la Educación de la República Argentina (CTERA). Faz parte de uma série de estudos que vêm se debruçando sobre as concepções de trabalho docente apresentadas por sindicatos docentes, principalmente aqueles que desenvolvem suas atividades no nível básico de ensino. A ideia central é conhecer algumas das interpretações feitas pelos sindicatos para a situação que a categoria vem vivendo, considerando-os agentes importantes na elaboração e discussão de propostas educacionais, especialmente em momentos de reformas e tentativas

* Agradeço à Coordenação de Aperfeiçoamento de Pessoal de Nível Superior (CAPES) pelo financiamento da investigação, na forma de bolsa de estágio pós-doutoral na Facultad Latinoamericana de Ciencias Sociales (FLACSO)/Argentina. de regulação do trabalho docente. Aliás, vários trabalhos têm constatado que, no que tange à elaboração e à implantação das reformas educacionais em curso desde os anos de 1990, os sindicatos docentes latinoamericanos têm sido pouco ouvidos (Filmus \& Tiramonti, 1998; Loyo, 2001; Murillo, 2001; Palamidessi, 2003). Esse é um fenômeno curioso, posto que, como é óbvio, a implementação de políticas educativas tem interferência direta sobre as condições de trabalho nas instituições escolares.

Meu propósito foi destacar quais os significados oferecidos por dirigentes da central sindical aos conceitos de "trabalhador em educação" e de "profissional docente”, em especial no recorte da investigação sobre o qual vou discorrer a seguir. Considero que a frequência com que têm sido usados os termos profissionalidade e/ou profissionalização docente na atual agenda educacional está a merecer mais análises a respeito do caráter polissêmico que esses termos vêm adquirindo.

Antes de ingressar no aspecto especificamente aqui discutido, vou explicitar sumariamente o percurso da pesquisa como um todo. Em primeiro lugar, com o intuito de visualizar o perfil do professorado argentino 
e conhecer as características do professorado abarcado pela CTERA, fiz uso de levantamentos realizados pela própria confederação sindical e pelo Ministerio de Educación, Ciencia y Tecnología da República Argentina, obtidos in loco e nas páginas eletrônicas da confederação e do referido Ministério; tal coleta foi complementada por pesquisa bibliográfica feita na base de dados da FLACSO/Argentina e do Proyecto Sindicalismo Docente y Reforma Educativa en América Latina.

Em segundo lugar, analisei documentos elaborados pela Confederação, com o propósito de perseguir ideias apresentadas sobre o significado do trabalho docente, tal como descrito em outro trabalho (Ferreira, 2008). Mantive, igualmente, interlocução com Deolidia Martínez, pesquisadora do Instituto de Investigaciones Pedagógicas "Marina Vilte” da CTERA, na tentativa de precisar os sentidos atribuídos pela organização aos termos "profissionalidade docente" e "trabalho docente”, entre outros. Ademais, como o tipo de estratégia metodológica implicou visitas frequentes à organização sindical, fiz uso de um diário de campo, com o propósito de registrar observações a respeito das atividades cotidianas da CTERA.

Em terceiro lugar, para conhecer estrutura, organização e referências programáticas da entidade sindical, desenvolvi entrevista semiestruturada gravada, realizada em duas ocasiões, com a secretaria Gremial da CTERA e o secretario de Política Institucional de Gestión Privada, ${ }^{1}$ membros da gestão 2001-2004.

Por fim, no que tange ao aspecto desenvolvido neste artigo, foram realizadas, em 2004, entrevistas semiestruturadas gravadas com três dirigentes da CTERA considerados bons informantes, ou seja, pessoas selecionadas em função de sua relevância para expor o assunto em questão (Haguette, 1997). Esses informantes não serão nomeados, já que suas contribuições estão sendo consideradas representações de caráter pessoal, isto é, não necessariamente programáticas. Entretanto, mais à frente serão fornecidas algumas características dos sujeitos.

\footnotetext{
${ }^{1}$ Professores Clelia Lavini e Luis Branchi.
}

Os motivos para a escolha de sindicalistas ligados à central argentina radicam na sua representatividade, brevemente explicada adiante, bem como na necessidade de realizar estudos comparativos sobre sindicatos de trabalhadores em educação na América Latina, tarefa que me parece pertinente e que vem sendo defendida por alguns autores, tais como Ibarrola e Loyo (2001).

\section{Referências teóricas para a análise dos dados}

Algumas das referências presentes em meus estudos sobre o trabalho docente serão agora resumidas, embora durante o texto outras contribuições teóricas apareçam inseridas na análise, de modo a colaborar na interpretação dos dados.

Primeiro, cabe sublinhar o interesse por desenvolver estudos acerca do trabalho docente que, por um lado, retomem algumas das principais temáticas que vêm sendo abordadas, como o problema da dicotomia entre proletarização e profissionalidade da docência, enquanto, por outro, busque incidir sobre a perspectiva de membros do professorado a respeito. Isso significa deter-se menos na análise do processo de trabalho docente propriamente dito e mais nas imagens e concepções presentes nos próprios sujeitos acerca de suas atividades (Bueno, 1998). Especialmente nesta pesquisa, os informantes-chave estão absolutamente inseridos na dicotomia examinada, por pertencerem a uma organização criada à imagem de entidade de trabalhadores manuais.

Um segundo aspecto refere-se à necessidade de recuperar a gênese da docência. Desse modo, é preciso destacar algumas de suas principais características (Birgin, 1999; Louro, 2001; Nóvoa, 1991): (1) o fato de que, a partir de meados do século XIX, tornou-se um trabalho eminentemente feminino e moldado segundo o que se divulga como particularidades das mulheres, o cuidado dos outros e a vocação - se bem que esta última se apresente como uma renovação da visão vocacional dos sacerdotes, responsáveis pelo início institucional da atividade. Além disso, (2) trata-se de uma ocupação cujo crescimento e organização se produzem como resultado da expansão da 
escolaridade capitaneada pelo Estado, ocorrida desde finais do século XVIII - no caso europeu, porque nos países da América Latina esse processo é posterior. Assim, o professorado, como categoria, só se constitui enquanto funcionalismo de Estado e passa a exigir formação específica a ser fornecida e certificada pelo próprio Estado.

Explicando melhor: a ampliação da escolarização, necessária para fazer funcionar uma produção capitalista cada vez mais carente de mão de obra minimamente educada e/ou adequada às exigências de homogeneização cultural em Estados que buscavam definir suas fronteiras, também foi exigindo a ampliação da categoria docente. Esse processo foi diferente no tempo conforme cada país e/ou continente. Mas, de forma genérica, temos uma expansão do ensino primário para segmentos mais amplos das populações, o que implicou a admissão de mais docentes, coincidindo com a feminização do magistério. O nível de renda reduzido, concomitante ao aumento do número de profissionais, foi subsumido na condição feminina do grupo, tendo em conta a convicção de que o salário das mulheres não seria o principal na constituição da renda familiar.

Isso inaugura uma etapa de modificações sociológicas na categoria, posicionada de forma ambígua na estrutura social, ao partilhar capital social derivado de seu capital cultural com determinados grupos, mas desprovida de renda suficiente para frequentar certos espaços da sociedade.

Mais adiante, as pressões sociais e o desenvolvimento econômico exigiram a ampliação dos níveis de ensino para setores menos elitizados durante as primeiras décadas do século XX. Segundo Nóvoa (1991), isso coincide com a euforia trazida pelos pressupostos da Escola Nova; euforia extinta em seguida pela eclosão e pelos resultados da II Guerra Mundial. Após esse momento, reformas educacionais levadas a cabo com base nas teorias do capital humano começaram um processo vivido até hoje, no qual o professorado é visto como simples executor de medidas pensadas sem sua colaboração ou consulta. Mas convém lembrar que, durante esse processo, se fabricou outra represen- tação da docência, a de professor-proletário, reforçada pelo surgimento e/ou fortalecimento de organizações docentes, criadas à semelhança daquelas que agrupam trabalhadores manuais.

Mais enfaticamente a partir dos anos de 1980, uma série de reformas ocorridas em vários países vem consolidando modificações substanciais no processo de trabalho docente. Na América Latina e no Caribe, essas reformas nos vêm alcançando desde os anos de 1990. Têm sido denunciadas por estudos com variados focos, alguns que se debruçam sobre o processo de trabalho e veem a docência em sua proximidade com um trabalho proletarizado (entre outros, Apple, 1987). Fundamentalmente tais estudos dirigiram-se ao grau de autonomia do professorado em sua atividade: a divisão do trabalho que acontece no mercado capitalista pode ser encontrada dentro da instituição escolar?

Por outra parte, outros trabalhos ocupam-se das características das reformas, indicando como principais aspectos a descentralização do sistema e de seu financiamento e modificações curriculares e da estrutura dos níveis do sistema de ensino (Oliveira, 2003; Tiramonti \& Filmus, 2001). Análises realizadas em diversos países indicam que uma consequência da implementação das reformas, dado que elas se realizam acompanhadas de ajuste fiscal e corte de recursos, é a piora das condições de trabalho e salários do professorado. Destaca-se, também, que a categoria docente não apenas não tem sido consultada sobre as modificações realizadas no sistema educacional como tem sido responsabilizada pelas dificuldades encontradas (Filmus \& Tiramonti, 1998; Loyo, 2001; Murillo, 2001; Palamidessi, 2003). Um tema então objeto dos discursos dos organismos responsáveis pelas reformas é a consideração de que os docentes necessitariam ser requalificados para enfrentar as novas exigências do mundo educacional (Barreto \& Leher, 2003; Krawczyk, 2002; Oliveira, 2003).

No que tange ao contexto examinado neste artigo, cabe dizer que as circunstâncias históricas que deram origem à categoria docente, bem como suas principais características e situação atual, podem ser encontradas também no caso argentino. Especificamente para o 
que me interessa relatar, sublinhe-se que o surgimento (1973) e posterior consolidação (pós-ditadura) ${ }^{2}$ de uma central do professorado na Argentina, a CTERA - que pode ser enquadrada numa perspectiva mais combativa dentro do movimento sindical -, permitem aferir as concepções de outras vozes sobre as reformas em curso e aquilo que se espera da atuação dos docentes. Em especial, pretendo apresentar os caminhos pelos quais representantes da entidade conceituam a situação do trabalho docente.

\section{Breve caracterização da CTERA}

Para compreender as características e significado que tem a CTERA no cenário educacional argentino, é necessário, ainda que sumariamente, retornar ao contexto histórico em que ela foi fundada. Ao analisar a organização sindical argentina, Giovine (2003) assinala três momentos distintos: o pré-institucional, o institucional ou sindicalismo de Estado e o pós-peronista, momento no qual se forma a CTERA. Com o golpe militar de 1955, que derrubou Perón, foi derrogado o Estatuto del Docente Argentino del General Perón e sancionado, em 1958, novo estatuto. Com base neste último, as províncias do país passaram a elaborar seus próprios estatutos, sendo este um momento de ampliação do número de organizações docentes e de crescimento do movimento docente (Gindin, 2008). Apesar da multiplicidade de organizações criadas, poucas contavam com o que se chama de personería gremial, ou seja, poucas estavam habilitadas a negociar pautas de reivindicações com os governos, adquirindo caráter eminentemente sindical.

Por esse motivo, passou a haver um esforço para diminuir a fragmentação das organizações docentes, criando-se em 1970 o Acuerdo de Nucleamientos Docentes (Gindin, 2008). Foi no bojo desse processo que se criou a CTERA, em agosto de 1973, no Congreso de la Unidad Docente, em Huerta Grande, Córdoba. Naquela ocasião, foram 146 os sindicatos que se filiaram

${ }^{2}$ A última ditadura, na Argentina, foi instituída em março de 1976, estendendo-se até dezembro de 1983. à organização. No entanto, desde 1989 acirrou-se um processo de unificação dos vários sindicatos existentes por jurisdição, de tal maneira que, na atualidade, a Confederação está integrada por entidades sindicais de primeiro grau conforme as jurisdições provinciais (23), da cidade de Buenos Aires e a jurisdição nacional, num total de 25 entidades, representando, em agosto de 2007, 286.385 associados.

A entidade agrupa sindicatos tanto do ensino público quanto do privado subvencionado pelo Estado, bem como admite sindicatos que representem tanto docentes quanto outros trabalhadores do sistema de ensino. Além disso, representa pessoas que não lecionam, mas que têm formação docente e ocupam cargos da carreira docente, como o de bibliotecário na escola primária, de preceptor ${ }^{3}$ na escola média, de auxiliar de direção e de diretor.

No que tange a formas organizativas e tipos de política sindical, a CTERA reivindica a organização pela base, com regras democráticas de funcionamento, buscando diferenciar-se de formas sindicais que, na história argentina, têm se expressado como simples extensões de partidos ou até mesmo dos próprios governos. Nesse sentido, a Junta Ejecutiva (Diretoria) é eleita por voto direto e secreto dos filiados das organizações de base, característica a sublinhar, no caso de uma confederação. Embora a mesma represente a chapa vitoriosa, nas demais instâncias da entidade podem fazer-se representar outras correntes políticas. O Consejo de Secretarios Generales, instância igualmente deliberativa, agrupa os cargos máximos de todos os sindicatos de base. E os congressos (ordinários e extraordinários) reúnem proporcionalmente, segundo a quantidade de filiados de cada sindicato, delegados para definir as políticas encaminhadas pela CTERA.

Esse formato organizacional foi obtido, segundo Gindin (2008), por meio da hegemonia da corrente sindical chamada de Celeste, o que converteu a CTERA

\footnotetext{
${ }^{3}$ Chama-se de preceptor o docente auxiliar na escola média,
} ou seja, o encarregado de suprir ausências de docentes ou colaborar com as tarefas que estes realizam, fora ou dentro de sala de aula. 
em uma confederação forte e homogênea, distante da interferência estatal.

Atualmente, está filiada à Internacional da Educação, à Confederação de Educadores Americanos e à Central de los Trabajadores Argentinos (CTA). Conta com o Instituto de Investigaciones Pedagógicas "Marina Vilte”, organismo que desenvolve estudos sobre os docentes e a situação educacional do país. Por meio da Escuela de Formación Pedagógica y Sindical “Marina Vilte”, promove cursos de aperfeiçoamento docente que inclusive são reconhecidos oficialmente para efeitos de ascensão na carreira. Realiza, periodicamente, os Congresos Educativos Nacionales, nos quais sistematiza discussões previamente preparadas por estudos disponibilizados a seus participantes.

É novamente Giovine que explicita a importância dessa organização para o desenho de uma nova identidade docente. Para ela, a criação da CTERA

\section{[...] constitui a expressão de um processo que [...] representa o trânsito da identidade docente de um papel de funcionário público ao de trabalhador do Estado. A docência faz parte, assim, de um campo sindical caracterizado por seu grau de heterogeneidade e fragmentação, no qual múltiplas articu- lações políticas e ideológicas na distribuição do poder vão medindo suas relações de força ao redor das disputas não só pela regulação da atividade docente mas também pela distribuição de recursos, que se traduz na colocação, em primeiro plano, da luta por melhorias salariais e condições de trabalho. (2003, p. 50)}

Desse modo, quanto aos mais recentes objetos das lutas da CTERA, o processo de reformas educativas - cujos eixos são a descentralização do sistema educacional e de suas fontes de financiamento - requer, como contrapartida do movimento sindical, uma organização bem maior na tentativa de encontrar interlocutores nos diversos governos contra os quais dirigir suas demandas. Ademais, frente à falta de interesse dos agentes governamentais em incluir o professorado no processo de reformas, as pautas de discussão têm que ser reorientadas no sentido de definir o papel dos docentes no sistema educacional e defender um tipo de formação que os habilite a ocupar esse lugar. Assim, para a CTERA, o trabalho docente torna-se central nesses debates.

\section{Articulando os conceitos de "trabalhador da educação" e de "profissional docente"}

A seguir discutirei resultados da análise no que tange às formas usadas pelos entrevistados para abordar o tema "trabalho docente". Para melhor visualização, o entrevistado e as entrevistadas foram identificados por seu sexo e por um número: H1, M1 e M2; o número de página junto às citações refere-se ao número da página da entrevista transcrita.

Cabe dizer, inicialmente, que os sujeitos são sindicalistas que começaram a militar em meio à ditadura, o que certamente deve explicar grande parte das trajetórias vividas. Considere-se que os movimentos sociais na Argentina da última ditadura foram cruelmente combatidos, dentre eles o movimento docente.

Os três entrevistados possuem formação como docentes de ensino fundamental, acrescida, mais tarde, de outros cursos; as mulheres começaram a trabalhar com menos idade que o homem. À altura das entrevistas, sua faixa etária estava entre os 54 e os 60 anos de idade. As mulheres são oriundas de províncias do interior da Argentina, o homem é da província de Buenos Aires.

Apesar de sua expressão em termos de movimento social com grande atuação no cenário argentino, nenhum deles tem militância partidária; somente uma indicou filiação a um partido, ainda que esclareça que não segue necessariamente as diretrizes partidárias na hora de eleição. Todos eles pertencem à Lista Celeste, corrente sindical hegemônica na condução da CTERA. Quanto à sua experiência sindical, além dos muitos anos de atividade, fator já indicado, sua participação nos cargos da entidade tem sido grande, o que denota as exigências feitas àqueles/as que decidem ser ativos na militância sindical, inclusive com a necessidade de deixar as salas de aula. M1 está há 9 anos sem lecionar; M2 está há 5 anos; e H1 está afastado de classes há 14 anos. 
As mulheres começam a trabalhar na docência muito jovens, ainda enquanto estudantes de magistério, com grande experiência em sala de aula e em setores escolares. Esse não é o caso do homem, que foi exonerado de seu cargo durante a ditadura. Assim, enquanto as mulheres puderam viver a escola com mais ênfase, apresentando um discurso mais apaixonado no que tange ao trabalho pedagógico, a permanência do homem em sala de aula é menor. Contudo, todos reconhecem a importância do trabalho pedagógico, como se verá por suas afirmações em torno do assunto.

\section{As identidades do professorado: "Discutir educação é discutir trabalho docente" ${ }^{\prime 4}$}

O primeiro elemento a destacar é a homogeneidade entre as concepções apresentadas pelos sindicalistas sobre a gênese da docência no país, também muito semelhantes àquelas encontradas na literatura específica (por exemplo: Birgin, 1999; Narodowski, 1997). Assim, para explicar as modificações nas representações e nas identidades docentes, os sujeitos partem da conhecida imagem do professor apóstolo. Discorrem, com riqueza de detalhes, sobre o impacto dessa imagem na configuração da docência, de Sarmiento ${ }^{5}$ até os dias atuais; esse professorado liberado de posições políticas e religiosas, envolvido apenas com a reprodução do conhecimento na escola, serviço doado, retribuído pela comunidade da melhor forma possível, embora sob a simples forma de oferecimento de produtos básicos para a subsistência.

Logo, dado que muitos docentes se considerariam profissionais da docência, os sindicalistas acreditam que esse termo, ao ser associado exclusivamente a uma concepção técnica da atividade, não permite perceber os aspectos políticos da educação e o resguardo no

${ }^{4}$ Fala de M2 (p. 3).

${ }^{5}$ Domingo Faustino Sarmiento, governador da província de San Juan (1862-1864), presidente do país (1868-1874), diretor geral de Escolas da província de Buenos Aires (1875), é considerado o principal impulsionador da ideia de que a educação seria uma das formas de constituir o Estado nacional. âmbito da vocação. Isto tem consequências: "ser apóstolo, mais que descrevê-lo teoricamente, é a atitude do professor em relação ao trabalho, como trabalha, como se envolve no trabalho; nisto se vê como apóstolo" (M1, p. 16).

A professora se vê como; a professora torna-se, então,

[...] uma espécie de sacerdotisa que devia transmitir o conhecimento, e que, pelo tipo de material com o qual trabalhava, que era as crianças, deveria manter-se em estado de pureza, isto é, não deveria contaminar-se com o que sucedia [...]; o conhecimento era neutro, e requeria, então, que aqueles que fossem seus transmissores deviam igualmente ser neutros. (H1, p. 8)

A análise dos sindicalistas continua a ser inserida no plano da constituição histórica das identidades, ao assinalar que essa imagem de docente

\section{[...] era correspondente, na Argentina, em termos políticos, a uma classe média que era muito permeável às ideias dos setores dominantes daquela época, onde, neste país, a classe média tinha um grau de bem-estar, de mobilidade ascendente bastante importante. E, então, a classe média era utilizada como uma espécie de colchão que geralmente atuava como uma massa isolante da classe trabalhadora, das demandas dos trabalhadores. (H1, p. 8)}

Assim, os docentes não se consideravam trabalhadores, mas uma "espécie de profissional liberal" (H1, M2). Contudo, há dois momentos históricos definidores de mudanças na identidade da docência argentina, segundo os sujeitos informantes.

Em primeiro lugar, estão os movimentos populares das décadas de 1960 e 1970, com os quais o professorado foi se identificando frente a, de um lado, o processo de pauperização da classe média e, de outro, à consciência adquirida quanto à ação dos setores dominantes do país e às ideologias administradas supostamente como democráticas e libertárias. Há também aqui, um corte geracional e outro corte de clas- 
se/gênero. O primeiro porque muitos jovens docentes tinham origem militante no movimento estudantil, rejuvenescendo as ideologias circulantes; de classe/ gênero porque, com a pauperização, o matrimônio das professoras ocorre com esposos de segmentos sociais não mais de classe média, mas de setores populares. $\mathrm{Na}$ avaliação de $\mathrm{H} 1$, o fato de que o salário das mulheres passou a corresponder à grande ou à maior parte da renda familiar interfere até nas formas de luta. É preciso que estas sejam mais objetivas, mais sérias, mais consequentes, pois a partir daí tornou-se impossível prescindir desse salário - no caso de corte de dias parados, por exemplo. É interessante notar que esta última manifestação do informante pode ser articulada a uma das interpretações que buscam contestar alguns dos mitos ou representações dominantes acerca da feminização da docência: a de que o salário das mulheres docentes veio para simplesmente complementar o salário de seus maridos ou ser destinado a gastos de caráter pessoal (Almeida, 1998). ${ }^{6}$ Além disso, ao considerar o trabalho das professoras uma necessidade social objetiva, colabora para questionar uma identidade calcada no caráter vocacional das mulheres à docência. As vocações não são atributos individuais; certos grupos sociais são encaminhados para uma ou outra ocupação segundo probabilidades objetivas, embora as representações majoritárias assegurem que se trata de opções pessoais. Assim, Catani, Bueno e Sousa (1998) afirmam que o encaminhamento das mulheres à docência corresponde mais a uma lógica de "destinação".

Em segundo lugar, há o período que se consubstancia com as reformas educacionais da década de 1990, que expressaria nova transformação nas imagens da docência. Uma das informantes chega a sublinhar a percepção de concepções diferenciadas de escola ou do papel da escola, quando se estabelece "uma nova classificação de docente, o docente frente à classe e o docente não-frente à classe, e quase estes [últimos]

${ }^{6}$ Ao contrário disso, afirma-se que "atualmente, não só a maioria dos lares de baixa renda como também a classe média são sustentados com o trabalho feminino” (Almeida, 2007, p. 217). eram colocados na condição de não-docentes” (M2, p. 3). Ela está abordando os embates em torno de concepções de carreira: enquanto a CTERA tem lutado para que todos e todas que se ocupam de tarefas na escola, tanto de sua gestão como dos aspectos pedagógicos, sejam considerados docentes e trabalhem articuladamente, o Estado tem procurado isolar as tarefas e seus executores e controlá-los de cima. Por isso, segundo ela, "discutir educação é discutir trabalho docente": porque não há como modificar as atribuições do Estado em matéria de educação sem transformar o objeto do trabalho docente e as formas de realizá-lo. E, nesse processo, estão em disputa imagens de docência.

Aqui, chegamos a outro elemento importante: no discurso dos sindicalistas, proletarização e profissionalidade docente são conceitos não excludentes. Eles são examinados tanto pela óptica econômica quanto pela óptica da autonomia sobre o trabalho realizado. A proletarização é fruto de uma situação de pauperização que empurra a antiga categoria, inserida por seu status nas classes médias, em direção ao status e às condições de vida de setores proletarizados. Mas o aspecto econômico seria insuficiente para explicar o fenômeno, se lembrarmos que os docentes, na gênese da ocupação, não sendo propriamente assalariados, eram pobres. O central é que a mudança do papel da escola se associa à não necessidade de um profissional capaz de realizar o seu trabalho de forma autônoma, e isso se expressa na (não) retribuição econômica, ambos aspectos presentes na versão proletária da docência. Um entrevistado explica assim a forma como, mais recentemente, a CTERA vem articulando os dois conceitos:

\footnotetext{
A condição profissional que estamos reivindicando, nós acreditamos que o docente tem que ter uma formação universitária, e tem que haver uma carreira profissional docente, e a identidade como trabalhadores. [...] Quando eu comecei a trabalhar, nós que colocávamos a natureza proletária do docente, renegávamos a condição desse docente como profissional. E hoje nós acreditamos que é preciso sintetizar as duas coisas, ou seja, que entendemos que não há contradição entre reivindicar a formação universitária para o docente e,
} 
ao mesmo tempo, colocar sua identidade como trabalhador

e seu compromisso como tal. (H1, p. 11)

Mais um detalhe: os sujeitos argumentam a existência de diferença de mentalidade entre o/a docente de escola primária e o/a de secundária: o segundo ganharia o dobro, podendo trabalhar em vários locais, considerando-se mais próximo de uma concepção "profissional individualista". Recordemos Morgade (1993), quando informa que a feminização da docência na Argentina, ocorrida no início do século passado, produziu-se mais no ensino primário, mantendo-se os homens no ensino médio e nos cargos diretivos. Sobre isso também assinala Birgin que os homens do ensino médio originalmente possuíam concepção vocacional diferenciada, dado já pertencerem ao funcionalismo de Estado: "em muitos casos tratou-se de magistrados, profissionais, pessoal hierárquico do sistema de educação primária, onde o vocacional adquiriu outro sentido, mais vinculado ao desenvolvimento da classe política” (1999, p. 28).

Tal ideia de constituição da categoria enquanto funcionários de Estado, passando, em poucas décadas, dessa condição à de simples empregados (funcionários assalariados mas desvalorizados) - que conduz a uma cisão na própria categoria -, é exemplificada pela consideração de que "nós, como setor, nos incorporamos num momento de forte retrocesso social dos trabalhadores no marco da nação” (M2, p. 10), isto é, o professorado chegou atrasado à constituição dos diferentes grupos sociais lutando por inclusão. Por esse motivo, "o docente médio, superior, universitário, quisera ser muito mais um profissional que um trabalhador" (idem, ibidem).

Em contrapartida, a proletarização pode ter sido alcançada no sentido criticado pelos sujeitos, como êxito na retirada da autonomia e da capacidade de reflexão. M1 diz que "a proletarização está se dando na atitude, não na cabeça; oxalá todos tivéssemos consciência de que somos trabalhadores” (p. 17). Segundo ela, o sentir-se tão pobre conduz ao abandono da formação e da qualidade das tarefas realizadas, ao “empobrecimento da dedicação ao trabalho”.
Retornarei a isso, mas por ora assinalarei outro problema. Conforme os sujeitos, apesar de todo o tempo de existência do sindicato e da filiação em massa, a identidade de trabalhador não é aceita por muita gente, achado que se assemelha àquele citado por Ferreira (2006) no tange à opinião de sindicalistas brasileiros/as ligados/as ao Centro dos Professores do Estado do Rio Grande do Sul/Sindicato dos Trabalhadores em Educação (CPERS/SINDICATO). No caso argentino, os motivos citados seriam especialmente de ordem ideológica, a baixa autoestima atribuída ao fato de considerar-se trabalhador/a. Segundo os referidos sindicalistas, contraditoriamente ao sentimento do professorado, a experiência indicaria que a reunião de docentes e funcionários num mesmo sindicato constitui-se numa vantagem para a organização, dado que a ausência de funcionários pode acentuar o caráter de classe média da base, que atuaria, assim, apenas "espasmodicamente", para usar o termo de H1 (há províncias em que o sindicato ligado à CTERA só filia docentes).

Sobre isso, M1 articula a falta de vontade de serem chamados, os professores, de trabalhadores em educação, à referida perspectiva sacerdotal e apolítica que a ocupação deveria ter, para alguns. É uma dificuldade que vem de décadas:

\footnotetext{
Os companheiros que ainda não aceitam que nos denominemos companheiros, entre nós, pelo universo trabalhista, pedem que lhes chamem 'colegas'. Dizem-te: 'por favor, aqui não nos diga companheiros, chame-nos colega'. Eh, e nós começamos a dar explicações para seguir dizendo companheiros, apesar dos 30 anos de estar trabalhando constituídos como sindicato em todas as províncias. Este processo tem a ver com uma formação política e ideológica do futuro docente nas escolas normais e nas escolas de formação. (M1, p. 16)
}

E H1 acrescenta que essa dificuldade de aceitar a realidade cria frustrações e prejudica os alunos: "não deixa de haver docentes que têm bolsos proletários e ainda celebram o que já não são, classe média..." (p. 13). 
Essas colocações são compatíveis com o apresentado por Apple, segundo o qual o professorado tem uma localização contraditória de classe. Ele não quer dizer, com isso, que por definição a categoria esteja nas classes médias ou ambiguamente posicionada, mas sim que, concordando com os trabalhos de Wright, "este grupo partilha [...] os interesses tanto da pequena burguesia quanto da classe operária” (Apple, 1987, p. 5).

Esse ponto nos dá abertura para passarmos à seção seguinte.

\section{Por que, então, os docentes se sindicalizam?}

Intimamente articulado à identidade de trabalhador, encontra-se o tema dos motivos para a sindicalização. Utilizo aqui a contribuição de Guerrero Serón (1991), para quem seriam três os principais motivos que conduziriam os docentes a filiar-se a sindicatos: os de ordem instrumental (atendendo a interesses de ordem pessoal), os solidários (em defesa dos interesses coletivos) e os ideológicos (em defesa das crenças).

Contudo, quando abordamos o caso argentino, cabe lembrar de uma particularidade histórica: o forte estímulo do peronismo à sindicalização, o que adicionaria à situação dos docentes mais uma variável na análise. Isso é o que nos diz uma das entrevistadas: "os docentes dessa geração que estamos trabalhando, não os das novas, não os das intermediárias, somos filhos daqueles peronistas que entenderam que havia que se agrupar para defender-se" (M1, p. 18). Quem está filiado por motivos ideológicos e/ou solidários pertenceria, então, a gerações mais antigas de docentes.

Afora isso, o principal motivo indicado para filiação é de ordem instrumental, com os docentes identificando-se mais com o sindicato na medida em que o vão conhecendo. A mesma professora comenta o assunto, acrescentando a interferência da sindicalização na formação de docentes:

\footnotetext{
[...] os docentes procuram o sindicato por uma necessidade pessoal e logo vão descobrindo um mundo que eles não conhecem. Agora, se nós temos professores no nível superior que estão sindicalizados, seguramente o aluno que se forma
}

como professor sai com outra concepção do que é um sindicato do que se tivesse um professor apóstolo. (M1, p. 18)

Então, se a consciência de trabalhador, que levaria diretamente à sindicalização, "é um erro na descrição da realidade” (idem, ibidem), os fatores que inicialmente conduzem a ela são o interesse pela capacitação fornecida pela entidade, por meio da Escola "Marina Vilte”, a riqueza das bibliotecas dos sindicatos, a possibilidade de realizar trâmites burocráticos, o acesso a planos de saúde subvencionados etc. Porém, paulatinamente, a aproximação vai se ampliando: "a sindicalização é um processo".

Essa ideia de processo também é desenvolvida pelos demais informantes. Para eles, maior grau de filiação ocorre em época de conflitos, tanto como forma de revolta contra as políticas neoliberais que privilegiam o individualismo e negam os projetos coletivos, como pela conviç̧ão de que estar dentro do sindicato permite certo grau de proteção quanto aos ajustes que essas políticas vêm tentando produzir. "Ou seja, há uma filiação, também na versão ideológica, importante" (H1, p. 14).

Ademais, por esse raciocínio, quem se filia mais é quem ganha menos e vive em piores condições; os que têm melhor salário já possuiriam outras formas de proteção social. Podemos comparar essas asserções com os achados de Tenti Fanfani (2005), para quem, na Argentina, os que têm maior probabilidade de participar em sindicatos são docentes que se definem como de classe baixa. Contudo, segundo o autor, “a participação ativa dos docentes na vida sindical parece estar mais associada ao capital cultural herdado da família e pela percepção de classe do que pela situação objetiva desses na estrutura de distribuição de renda" (p. 223). Esse é um achado que certamente mereceria maiores estudos.

\section{Educação como direito: “A escola é o espaço público que ainda nos sobra"7}

Do dito até agora depreende-se que a identidade docente foi sendo abordada pelos informantes tentan-

\footnotetext{
${ }^{7}$ Fala de M2 (p. 8).
} 
do lançar luz sobre aspectos da natureza do trabalho realizado pelo professorado. Tal percepção leva a pensar que há uma especificidade no tratamento da profissionalidade docente sempre que esta é associada ao tipo de escola desejada. Para os sujeitos, é impossível discutir trabalho docente sem discutir escola pública de qualidade para todos e melhor formação profissional dos docentes. Mas essa formação deve ser providenciada pela entidade, já que o Estado possui interesses diferentes e dá outro sentido à questão da profissionalidade:

E sabemos que temos que apostar numa forte formação do trabalhador para que a escola leve adiante um projeto que sirva ao povo, [...] que recupere sua identidade de escola pública. Quando nós decidimos isto, recuperamos um papel sindical, como aqueles que existiram nos primeiros tempos, no sindicato se peleava pelos direitos e se peleava pelo trabalho e se formavam os aprendizes. Nós dizemos, os sindicatos primários formavam, os sindicatos por ofício, formavam os jovens no ofício. Nós queremos recuperar isto e incidir fortemente no trabalho de formação, ou para ajudar a crescer no ofício de ensinar, aos trabalhadores da educação, não somente se é justo teu salário, não somente como entras na escola, não somente como [fazer os concursos], mas também como somos melhores trabalhadores. (M1, p. 20-21)

A reivindicação das questões específicas do professorado, portanto, não pode se dar apenas no plano econômico, porque a agressão que os trabalhadores em educação estariam sofrendo por parte das políticas neoliberais é agressão à ideia de educação pública como um todo: as reivindicações só fazem sentido inseridas num conjunto de proposições para recuperar a escola pública, definida como "a escola que pertence ao povo" (idem, ibidem). ${ }^{8}$ E esses trabalhadores têm que ser capazes de levar adiante projetos educativos.

${ }^{8}$ Os entrevistados deixam claro que essa perspectiva mais ampla de compreensão da ação sindical e docente não é unânime, sofrendo resistências também dentro do sindicato: há quem considere que este deveria dedicar-se exclusivamente a questões salariais e de condições de trabalho.
Assim, uma grande parcela do êxito dos estudantes pode ser alcançado pela qualidade do trabalho dos docentes: "as crianças conhecem muito, têm conhecimentos prévios ainda nas piores condições em que estejam, e os resultados dependem muitíssimo das práticas docentes e dos imaginários dos docentes sobre a perspectiva das crianças” (M2, p. 8).

Por isso, a entidade tem investido fortemente na formação docente. Não é apenas porque os governos não o fazem, não é só por fazer parte dos anseios dos docentes, é porque não haveria outra forma de fazer avançar um projeto educacional na perspectiva da maioria da população versus a posição minimalista do Estado neoliberal. Para os dirigentes da CTERA, educação pública de qualidade e valorização do trabalho docente são duas faces da mesma moeda, e para tanto há que melhorar a formação de docentes. De fato, sabe-se que a CTERA tem uma incisiva política de formação continuada, que ocorre por meio de cursos de aperfeiçoamento realizados em conjunto com universidades do país, com ferramentas de formação a distância, utilizando sua página na internet, em congressos e publicações etc. ${ }^{9}$

Ademais, assinalam que é o governo, na condição de patrão, que pretende colocar em oposição a profissionalidade do professorado e sua organização em sindicatos: "O Estado tem jogado sempre com a ideia de... contrapor o conceito de profissionalidade ao conceito de agrupamento coletivo para defender interesses, digamos, de classe" (H1, p. 17). E, nessa ótica, o Estado confunde diferentes conceitos de profissionalização, ora tomando-a no sentido liberal, tal como os Conselhos de Professores, tornados obriga-

\footnotetext{
9 Segundo Gutiérrez e Priotto (2008), a Escuela “Marina
} Vilte", existente desde 1993, foi pensada para ser "um instrumento para a conformação da política educativa do país, instrumento de ação político-pedagógica no conjunto dos docentes; enfatizando especialmente a formação do professorado em serviço, sendo outra de suas tarefas a formação de dirigentes no seio das instituições educacionais" (p. 548). Veja-se também Ferreira (2008), bem como as próprias páginas da organização na internet: http://www.escuelamarinavilte.org.ar/ e http://www.ctera.org.ar/iipmv/index.html. 
tórios pelas ditaduras militares - o exemplo clássico citado é o caso do Chile -, ora associando o conceito à ideia de produtividade, mais adequada a uma versão mercadológica de trabalho.

Os sujeitos estão de acordo que formação não é apenas treinamento para o exercício das tarefas, entendidas como atividades práticas, mas para a pesquisa e a reflexão sobre o próprio trabalho. Argumentam sobre o esvaziamento das tarefas pedagógicas, tendo o professorado que se envolver cada vez mais com demandas relacionadas à pobreza de seus alunos.

Contudo, somente M2 opera com a ideia de que a falta de identificação da atividade docente como trabalho ocorre porque a maioria que a realiza é mulher. ${ }^{10}$ Essa desconsideração é oriunda da imagem majoritária da docência, compartilhada pelas professoras, ao não reconhecerem seu ofício como trabalho, assumindo-o como uma extensão das atividades domésticas. Ela faz uma dura crítica às/aos próprias/os trabalhadoras/ es docentes, no caso, colegas, como:

[...] um psicopedagogo, um psicólogo, o que seja, lhe buscamos um espaço de trabalho, lhe damos um tempo de trabalho, um lugar, um tempo, um silêncio, um reconhecimento especial que não damos a nós mesmos. E o governo, da mesma forma; isto é, todo o trabalho profissional é negado. Eu creio que aqui entra muito o de mulher, não? Ou seja, entra muito a condição de mulher. [...] Este trabalho docente que está metido, primeiro - dizemos -, na caixa negra do mágico, é como se ninguém soubesse, temos como se faz um exercício, a seleção de uma antologia, o conto, a aula, mas... muito de doméstico. Por quê? Porque nós nem ao menos o registramos, porque não nos damos o tempo, o lugar, a situação de pensar o trabalho. Vamos pensando nele na medida em que o fazemos, $[. .$.$] não há tempo para$ refletir sobre o próprio trabalho. (M2, p. 11)

${ }^{10}$ A invisibilidade da docência como trabalho feminino, tanto na literatura acadêmica como entre sindicalistas docentes, tem sido discutida por várias autoras. Veja-se, por exemplo: Bruschini e Amado (1988); Vianna (2001); Ferreira (2004).
Tal reflexão pode gerar muitos frutos; em primeiro lugar, no que tange à docência como ocupação feminina. Como já dito a partir do pronunciamento de H1 sobre mudanças na identidade docente, a representação da docência como atividade de extensão das tarefas do lar, dado que exercida majoritariamente por mulheres, contribuiu para fixar a ideia de que esse trabalho tem status menos profissional, no sentido de menos cultivado intelectualmente e mais relacionado a dotes naturais presentes nas mulheres e de acordo com seu suposto papel social, "uma espécie de treinamento com os filhos dos outros" (Fernández Enguita, 2004, p. 110). Além disso, é uma imagem que terminou por apropriar-se da ocupação, independentemente do sexo de quem a exerce (Carvalho, 2000). A concepção sobre as especificidades de comportamentos e vocações segundo os sexos apela para a natureza como moldadora dos mesmos; a cultura como produtora desses comportamentos está fora de questão, segundo a representação majoritária. Essa é uma forma sutil de encaminhar determinadas pessoas, especialmente do sexo feminino, para profissões desvalorizadas socialmente (Bruschini \& Amado, 1988). Entretanto, há de se convir que, do ponto de vista histórico, a docência foi uma forma, com certo prestígio, que as mulheres encontraram para sair aos espaços públicos.

Em segundo lugar, podemos abordar a concepção que compreende o ensino como um ofício sem saberes, considerada um obstáculo para a emergência de saberes específicos da profissão docente, tal como indicam as investigações de, por exemplo, Gauthier (1998) e Tardif (2002). A informante esclarece esse obstáculo, a dificuldade de definir o que é inerente ao ensino e o que é pertinente àquele que ensina, pelo próprio professorado. Embora árdua, a procura pelo repertório de conhecimentos que compõem o ofício docente pode lançar luz sobre essa identidade ocupacional. Os autores citados indicam uma série de saberes presentes no cotidiano da atuação docente provenientes de diversas fontes, como os saberes disciplinares, os da ciência pedagógica, os curriculares, os da tradição pedagógica, os saberes da experiência e o da ação pedagógica. A análise dos saberes no cotidiano da prática pedagógica 
pode fornecer instrumentos para que o professorado possa alçar sua voz na procura de profissionalização, sempre que consiga validar a importância de seus saberes frente à sociedade (Gauthier, 1998).

Há uma última questão pertinente quanto ao tipo de relação que o professorado estabelece com seu trabalho. Trata-se, ainda, de mais uma possível interpretação sobre a proletarização do trabalho docente. Os sindicalistas referem-se à alteração do tipo de trabalho que a docência deve realizar à medida que aumenta a miséria da população e o Estado se desobriga de suas funções sociais, diminuindo sua presença e homogeneizando as atividades de distintas categorias de trabalhadores sociais. Logo, à escola chegam inúmeras necessidades não relacionadas ao ensino propriamente dito. Para M2, seria tarefa do professorado orientar as demandas - e não encarregar-se delas. Mas o problema central, nessa fuga das atividades pedagógicas para as assistenciais, é que os docentes vão ficando fartos e caem no extremo oposto, que é a dessensibilização e o desinteresse, fazendo o mínimo possível: "creio que agora, na Argentina, isto está produzindo uma ruptura, uma má ruptura. $\mathrm{O}$ docente diz 'basta, já não me encarrego de nada, é meu trabalho, ocupo-me [apenas] de minhas horas'” (M2, p. 14) -, algo semelhante ao que disse M1, algumas páginas atrás, quando define proletarização como empobrecimento da dedicação ao trabalho.

Talvez possamos interpretar esse problema na óptica apresentada por Derber (apud Jiménez Jáen, 1991) acerca da diferença entre proletarização técnica e ideológica, a primeira relativa à perda de controle sobre o processo de trabalho propriamente dito, a segunda referindo-se à falta de controle sobre os fins do trabalho, ou seja, seus propósitos sociais. Nessa abordagem, o processo desqualificador do professorado ocorreria mais quanto ao segundo tipo de proletarização, porque, quanto ao primeiro, o tipo de desqualificação não é idêntico ao que sofrem os demais trabalhadores, já que não afeta a totalidade de suas tarefas; na verdade, esses trabalhadores passariam por processos de requalificação para adaptar-se às novas competências exigidas a partir da racionalização de seu trabalho.
Nesse sentido, o professorado mantém o controle sobre o planejamento de sua atividade de sala de aula, mas não tem poder sobre o planejamento do processo educativo como um todo. À medida que se produz esse afastamento da visão global da educação desenvolvida, há a possibilidade de ocorrer uma "dessensibilização ideológica”, mecanismo de acomodação pelo qual se adquire a "crença de que a educação constitui um trabalho 'técnico', cujos problemas devem ser resolvidos 'tecnicamente', deixando de lado suas facetas políticas e ideológicas" (Jiménez Jáen, 1991, p. 85). A autora acrescenta que "a dominação ideológica em educação requer uma efetiva autoidentificação dos protagonistas do processo educacional com as técnicas e conteúdos de um modelo educacional dado" (p. 86), embora sublinhe que esse consentimento nunca é total nem está assegurado desde sempre.

Ora, a CTERA parece reconhecer esse tipo de problema, ou de proletarização, e por meio de processos de formação incisivos, como foi aqui exemplificado, tem procurado atacar a falta de reflexão dos docentes a respeito de seu próprio trabalho. É isso que se percebe no documento resultante de um de seus congressos pedagógicos, onde se explicita que o processo de formação docente:

\section{[...] deve assentar-se numa sólida formação geral, que integre os conhecimentos científico-tecnológicos e os do campo de trabalho, necessários para compreender com uma visão crítica que permita modificar os complexos processos produtivos que caracterizam, hoje, o mundo do trabalho e que, além disso, possibilitem [ao trabalhador] manter-se atualizado sobre os mesmos. Em tal sentido, o trabalhador da educação deve manter seu papel de trabalhador intelectual criador e transmissor da cultura na qual está imerso e que representa significativamente, consciente da influência que exerce numa sociedade carente de referências. (Congreso Educativo Nacional de La CTERA, 1999, grifos meus)}

\section{Para finalizar}

Poderíamos pensar que a recusa dos docentes a serem chamados de trabalhadores em educação 
possa manter relação com uma adesão ideológica a propósitos educacionais elaborados acima do sistema e sem sua participação efetiva. Nessa óptica, os docentes resistiriam aos processos de desqualificação que sofrem, mas não enquanto proletários e sim contra serem tratados como proletários, como argumentam Gorz (apud Jiménez Jáen, 1991, p. 84) e Fernández Enguita (2004).

Mas também é preciso prestar atenção aos diversos sentidos que podem ser atribuídos aos termos profissionalidade ou profissionalismo e que implicam estratégias de caráter contraditório. Já vimos as críticas feitas pelos sindicalistas à concepção de profissionalismo segundo o Estado. Fernández Enguita (2004) e Jiménez Jáen (1991) sublinham o caráter reacionário da ideia de profissão docente sempre que isso significar uma atitude contrária à participação da sociedade civil ou da comunidade escolar nas decisões relativas à problemática educacional, ficando somente os docentes como interlocutores das autoridades. Por outra parte, essa não parece ser a posição expressa pelos sindicalistas da CTERA. Ao contrário, elas e ele somente inserem a perspectiva de ampliação da profissionalização do professorado a partir do envolvimento deste com as necessidades educacionais da população.

Portanto, retornando ao objeto principal do artigo esclarecer os significados que os dirigentes da CTERA dão aos conceitos de "trabalhador em educação" e de "profissional docente" -, é possível dizer que para ele e elas não há contradição entre ser trabalhador e buscar a profissionalidade. A defesa que fazem da identidade de trabalhador em educação articula a luta contra a retirada de direitos trabalhistas e o papel protagônico dos professores e professoras no desenvolvimento de projetos educacionais. Mas esse trabalhador/profissional pode ser assim definido porque não se entende o "profissional" como aquele que representa um papel exclusivamente técnico e individualizado e, sim, coletivo e visando os interesses dos grupos mais desfavorecidos da sociedade. Se esse trabalho coletivo incorporaria também, segundo os dirigentes da CTERA, a gestão educacional pela comunidade escolar é um aspecto a ser investigado futuramente.

\section{Referências bibliográficas}

ALMEIDA, Jane S. de. Ler as letras: por que educar meninas e mulheres? São Bernardo do Campo: UNIMEP; Campinas: Autores Associados, 2007.

. Mulher e educação: a paixão pelo possível. São Paulo: UNESP, 1998.

APPLE, Michael. Relações de classe e de gênero e modificações no processo do trabalho docente. Cadernos de Pesquisa, São Paulo, n. 60, p. 3-14, fev. 1987.

BARRETO, Raquel; LEHER, Roberto. Trabalho docente e as reformas neoliberais. In: OLIVEIRA, Dalila (Org.). Reformas educacionais na América Latina e os trabalhadores docentes. Belo Horizonte: Autêntica, 2003. p. 39-60.

BIRGIN, Alejandra. El trabajo de enseñar; entre la vocación y el mercado: las nuevas reglas del juego. Buenos Aires: Troquel, 1999. BRUSCHINI, Cristina; AMADO, Tina. Estudos sobre mulher e educação: algumas questões sobre o magistério. Cadernos de Pesquisa, São Paulo, n. 64, p. 4-13, fev. 1988.

BUENO, Belmira. Pesquisa em colaboração na formação contínua de professores. In: ; CATANI, Denice; SOUSA, Cynthia.

(Orgs.). A vida e o ofício dos professores; formação contínua, autobiografia e pesquisa em colaboração. São Paulo: Escrituras, 1998. p. 7-20. CARVALHO, Marília. Gênero e política educacional em tempos de incerteza. In: GANDIN, Luís Armando; HYPOLITO, Álvaro Moreira (Orgs.). Educação em tempos de incertezas. Belo Horizonte: Autêntica, 2000. p. 137-162.

CATANI, Denice; BUENO, Belmira; SOUSA, Cynthia. Os homens e o magistério; as vozes masculinas nas narrativas de formação. In: BUENO, B.; CATANI, D.; SOUSA, C. (Orgs.). A vida e o ofício dos professores; formação contínua, autobiografia e pesquisa em colaboração. São Paulo: Escrituras, 1998. p. 45-64.

CONGRESO EDUCATIVO NACIONAL DE LA CTERA, 2., Buenos Aires, 1999. Documento final. Disponível em: <http:// web.wamani.apc.org/aa180/img_upload/efdda831483156d55ea631 ca8ae76d0f/IICongresoEducativodeCTERA.pdf $>$. Acesso em: 14 nov. 2008.

FERNÁNDEZ ENGUITA, Mariano. Educar em tempos incertos. Porto Alegre: Artes Médicas, 2004.

FERREIRA, Márcia O. V. Importancia y significados de la cualificación docente para una central de trabajadores de la educación. El caso de la CTERA (Argentina). Revista Mexicana de Investigación Educativa, México, v. 13, n. 37, p. 505-527, abr.jun. 2008. 
Mulheres e homens em sindicato docente: um estudo de caso. Cadernos de Pesquisa, São Paulo, v. 34, n. 122, p. 391410, maio/ago. 2004.

Somos todos trabalhadores em educação? Reflexões sobre identidades docentes desde a perspectiva de sindicalistas. Educação e Pesquisa, São Paulo, v. 32, n. 2, p. 225-240, maio/ ago. 2006.

FILMUS, Daniel; TIRAMONTI, Guillermina. Presentación del proyecto: conformación del grupo de trabajo Sindicalismo Docente y Reforma Educativa en América Latina. Boletín Proyecto Sindicalismo Docente y Reforma Educativa en América Latina, Buenos Aires, n. 1, p. 1-2, 1998.

GAUTHIER, Clermont et al. Por uma teoria da pedagogia; pesquisas contemporâneas sobre o saber docente. Ijuí: Editora da UNIJUÍ, 1998.

GINDIN, Julián. Sindicalismo docente en México, Brasil y Argentina: una hipótesis explicativa de su estructuración diferenciada. Revista Mexicana de Investigación Educativa, México, v. 13, n. 37, p. 351-375, abr./jun. 2008.

GIOVINE, Renata. Sindicalismo y gobierno: una agenda para el diálogo sobre la reforma educativa; el caso de Argentina. Proyecto Sindicalismo Docente y Reforma Educativa en América Latina. Buenos Aires: PREAL-FLACSO, 2003.

GUERRERO SERÓN, Antonio. ¿Por qué el profesorado no se sindica? In: SÁNCHEZ, J. M. (Ed.). La sociología de la educación en España. Madrid: J.M.S. Editor, 1991. p. 187-195.

GUTIÉRREZ, José; PRIOTTO, Guillermo. Estudio de caso sobre un modelo de desarrollo curricular descentralizado en Educación Ambiental para la sustentabilidad. Revista Mexicana de Investigación Educativa, México, v. 13, n. 37, p. 529-571, abr./jun. 2008. HAGUETTE, Teresa. Metodologias qualitativas na sociologia. 5. ed. Petrópolis: Vozes, 1997.

IBARROLA, María de; LOYO, Aurora. Estructura del sindicalismo docente en América Latina. In: TIRAMONTI, G.; FILMUS, D. (Coords.). Sindicalismo docente \& reforma en América Latina. Buenos Aires: FLACSO/Temas, 2001. p. 71-110.

JIMÉNEZ JÁEN, Marta. Os docentes e a racionalização do trabalho em educação; elementos para uma crítica da teoria da proletarização dos docentes. Teoria e Educação, Porto Alegre, n. 4, p. 74-90, 1991. KRAWCZYK, Nora. A sustentabilidade da reforma educacional em questão: a posição dos organismos internacionais. Revista Brasileira de Educação, Rio de Janeiro, n. 19, p. 43-62, jan./abr. 2002.

LOURO, Guacira. Mulheres na sala de aula. In: DEL PRIORE,
Mary (Org.). História das mulheres no Brasil. 5. ed. São Paulo: UNESP/Contexto, 2001. p. 443-481.

LOYO, Aurora. Los sindicatos docentes en América Latina: entre la lógica laboral y la lógica profesional. Revista Iberoamericana de Educación, Madrid, n. 25, p. 65-81, 2001.

MORGADE, Graciela. ¿Quiénes fueron las primeras maestras? Revista de IICE, Buenos Aires, año 2, n. 2, p. 52-60, jul. 1993.

MURILLO, María Victoria. Sindicalismo docente en América Latina: aproximaciones al estado del arte. In TIRAMONTI, G.; FILMUS, D. (Coords.). Sindicalismo docente \& reforma en América Latina. Buenos Aires: FLACSO/Temas, 2001. p. 35-70. NARODOWSKI, Mariano. Para volver al Estado; del pedagogo de Estado al pedagogo de la diversidad. Propuesta Educativa, Buenos Aires, n. 17, p. 51-55, 1997.

NÓVOA, António. Para o estudo sócio-histórico da gênese e desenvolvimento da profissão docente. Teoria \& Educação, Porto Alegre, n. 4, p. 109-139, 1991.

OLIVEIRA, Dalila. As reformas educacionais e suas repercussões sobre o trabalho docente. In: OLIVEIRA, Dalila (Org.). Reformas educacionais na América Latina e os trabalhadores docentes. Belo Horizonte: Autêntica, 2003. p. 35-70.

PALAMIDESSI, Mariano. Sindicatos docentes y gobiernos: conflictos y diálogos en torno a la Reforma Educativa en América Latina. Documentos PREAL, Santiago, n. 28, 2003.

TARDIF, Maurice. Saberes docentes e formação profissional. Petrópolis: Vozes, 2002.

TENTI FANFANI, Emilio. La condición docente; análisis comparado de la Argentina, Brasil, Perú y Uruguay. Buenos Aires: Siglo XXI, 2005.

TIRAMONTI, Guillermina; FILMUS, Daniel (Coords.). Sindicalismo docente \& reforma en América Latina. Buenos Aires: FLACSO/Temas, 2001.

VIANNA, Cláudia. A produção acadêmica sobre organização docente: ação coletiva e relações de gênero. Educação \& Sociedade, Campinas, n. 77, p. 100-130, dez. 2001.

MÁRCIA ONDINA VIEIRA FERREIRA, doutora em sociologia pela Universidad de Salamanca (Espanha), com pósdoutorado na Facultad Latinoamericana de Ciencias Sociales (Argentina), é professora do Programa de Pós-Graduação em Educação da Faculdade de Educação da Universidade Federal de Pelotas (UFPel). Publicações recentes: Importancia y significados de la cualificación docente para una central de trabajadores de la 
educación. El caso de la CTERA (Argentina) (Revista Mexicana de Investigación Educativa, v. 13, p. 505-527, 2008); Desconforto e invisibilidade: representações sobre relações de gênero entre sindicalistas docentes (Educação em Revista, v. 47, p. 15-40, 2008); Notas sobre as relações entre identidade e sindicalismo docentes (Educação e Sociedade, v. 28, p. 377-399, 2007); Somos todos trabalhadores em educação? Reflexões sobre identidades docentes desde a perspectiva de sindicalistas (Educação e Pesquisa, v. 32, p. 225-240, 2006); "Siempre el destino acaba llevándonos hacia donde tenemos que estar": trayectorias escolares y profesionales de profesoras y profesores militantes (In: Políticas educativas y trabajo docente: nuevas regulaciones ¿nuevos sujetos? Buenos Aires: Novedades Educativas, 2006. p. 143-160). Projetos de pesquisa em andamento, ambos com financiamento do Conselho Nacional de Desenvolvimento Científico e Tecnológico (CNPq): "Diretoras/es do $24^{\circ}$ Núcleo do CPERS/SINDICATO: trajetórias educacionais, profissionais e sindicais segundo o gênero" e "Relações de gênero e sexualidades no campo da educação. Uma análise a partir da produção da ANPEd”.E-mail: marciaof@ufpel.edu.br

Recebido em março de 2008 Aprovado em março de 2009 
Key words: connection between academic activities; teaching, research and extension; post graduation.

Enseñanza-investigación-extensión: práctica de la inseparabilidad en la pos-graduación

Se discute la inseparabilidad enseñanza-investigación-extensión como un principio orientador de la calidad de la producción universitaria. Aunque se reconozca la importancia de articulaciones duales (entre enseñanza e investigación, investigación y extensión o extensión y enseñanza), se defiende un principio que impide los reduccionismos verificados en las actividades universitarias. Guiados por esa comprensión, durante la práctica de docencia, los autores realizaron un ejercicio de inseparabilidad, que consistió en una experiencia enfocando relacionar el conocimiento cientifico y el saber de educadores y educandos de una escuela pública en João Pessoa (PB), a fin de obtener conocimiento acerca de la articulación entre relaciones de género, violencia y juegos electrónicos. Se defiende que la inseparabilidad entre enseñanza, investigación y extensión aún no se toma en cuenta en la práctica de muchos docentes, sea porque en la graduación se da énfasis a la enseñanza, sea porque en la pos-graduación el énfasis cae en la investigación. Se argumenta, además, que la práctica de docencia en la pos-graduación es una excelente oportunidad para practicar la inseparabilidad defendida.

Palabras-claves: inseparabilidad entre enseñanza; investigación y extensión; pos-graduación; práctica de docencia.

Márcia Ondina Vieira Ferreira

"Discutir educação é discutir trabalho docente": o trabalho docente segundo dirigentes da Confederación de Trabajadores de la Educación de la República Argentina (CTERA)

Inserido nos debates a respeito da dicotomia entre "proletarização" e "profissionalidade" do trabalho docente, o texto destaca significados oferecidos por dirigentes da CTERA aos conceitos de "trabalhador em educação" e de "profissional docente". Os dados foram obtidos por meio de entrevistas semiestruturadas, realizadas com um homem e duas mulheres. O referencial sustenta-se em análises que interpretam a gênese da ocupação como forma de compreender sua atual configuração; o processo de trabalho docente; e a importância do gênero para tecer as representações existentes sobre a ocupação. Os resultados indicam que, na elaboração dos sindicalistas, não há contradição entre ser trabalhador e buscar a profissionalidade. A defesa da identidade de trabalhador em educação articula a luta contra a retirada de direitos trabalhistas e o papel protagonista do professorado no desenvolvimento de projetos educacionais.

Palavras-chave: trabalho docente; sindicalismo docente; profissionalidade docente; trabalhadores em educação; CTERA.

\section{"Discussing education is discussing the teaching work": the teaching work according to Confederación de Trabajadores de la Educación de la República Argentina (CTERA) coordinators}

Inserted in the debates concerning the dichotomy between "proletarianization" and "professionality" of the teaching work, the text highlights meaning offered by the CTERA coordinators to the concepts of "education workers" and of "teaching professional". The data were obtained through semistructured interviews, done with a man and two women. The referential is based on analysis which interpret the genesis of the occupation as a way to understand its present configuration; the process of the teaching work; and the importance of the gender in order to compose the existing representations on the occupation. The results indicate that, in the elaboration of union members, there is no contradiction between being a worker and seeking the professionality. The defense of the identity of the education worker articulates the fight against the removal of working rights and the protagonic role of the teachers in the development of educational projects.

Key words: teaching work; teacher unionism; teacher professionality education; workers; CTERA.

"Discutir educación es discutir trabajo docente": el trabajo docente según sindicalistas de la Confederación de Trabajadores de la Educación de la República Argentina (CTERA)

Formando parte de los debates acerca de la dicotomía entre “proletarización” y "profesionalidad" del trabajo docente, este artículo destaca significados ofrecidos por sindicalistas pertenecientes a la CTERA a los conceptos de "trabajador de la educación” y "profesional docente". Los datos fueron obtenidos por medio de entrevistas semiestructuradas, realizadas con un hombre y dos mujeres. El marco teórico está basado en análisis que interpretan la génesis del oficio como forma de comprender su actual configuración; el proceso de trabajo docente; y la importancia del género para construir las representaciones existentes sobre el oficio. Se constata que, para los sindicalistas, no hay contradicción entre ser trabajador y buscar la profesionalidad. La defensa de la identidad de trabajador de la educación articula la lucha en contra de la reducción de derechos laborales y el protagonismo del profesorado en el desarrollo de proyectos educativos. 
Palabras-claves: trabajo docente; sindicalismo docente; profesionalidad docente; trabajadores de la educación; CTERA.

Maria da Graça Jacintho Setton

A socialização como fato social total: notas introdutórias sobre a teoria do habitus

O objetivo deste artigo é refletir sobre o processo de socialização segundo a perspectiva da sociologia da educação. Mais precisamente, pensar a teoria da socialização a partir de um ponto de vista relacional, articulando as principais agências educativas da atualidade. Para melhor compreender o fenômeno da socialização contemporânea, propõe-se pensar essa prática como um fato social total, isto é, uma prática social vivida por uma dinâmica processual a partir da troca de bens e mensagens simbólicos entre agências e agentes socializadores, que envolve simultaneamente todos os indivíduos com a tarefa de manter o contrato e o funcionamento da realidade social. Para desenvolver esse argumento, darse-á ênfase a duas teorias da ação que discutem o processo de socialização: a primeira se refere à teoria do habitus, de Pierre Bourdieu; a segunda, àquela desenvolvida por Bernard Lahire que, em uma interpretação particular e crítica a Bourdieu, propõe uma leitura contemporânea da socialização, cunhando a expressão homem plural.

Palavras-chave: fato social total; habitus; homem pural.

\section{Socialization as a total social fact:} introductory notes on the theory of habitus

The objective of this article is to reflect upon the process of socialization from the perspective of the sociology of education. More precisely, to discuss the theory of socialization starting from the relational point of view and articulating the chief current educational agencies. In order to understand better the phenomenon of contemporary socialization, we propose to consider this practice as a total social fact, that is, a social practice lived by a procedural dynamic based on an exchange of goods and symbolic messages between socializing agencies and agents which simultaneously involve all individuals in the task of maintaining the contract and the functioning of social reality. In order to develop this argument, we emphasize two theories of action which discuss the process of socialization: the first refers to Pierre Bourdieu's theory of habitus and the second to that developed by Bernard Lahire who, in a critical interpretation of Bourdieu, proposes a contemporary reading of socialization, coining the expression plural man.

Key words: total social fact; habitus; plural man.

\section{A socialización como hecho social} total: notas introductorias sobre la teoría del habitus

El objetivo de este artículo es reflexionar sobre el proceso de socialización según la perspectiva de la sociología de la educación. Pero precisamente, pensar la teoría de la socialización a partir de un punto de vista relacional, articulando las principales agencias de educación de la actualidad. Para mejor comprender el fenómeno de la socialización contemporánea, se propone pensar esa práctica como un hecho social total, esto es, una práctica social vivida por una dinámica procesal a partir del cambio de bienes y mensajes simbólicos entre agencias y agentes socializadores, que abarca simultáneamente todos los individuos con la tarea de mantener el contrato y el funcionamiento de la realidad social. Para el desarrollo de este argumento, se le dará énfasis a dos teorías de la acción que discuten el proceso de socialización: la primera se refiere a la teoría do habitus, de Pierre Bourdieu; la segunda, aquella dessarrollada por Bernard Lahire que, en una interpretación particular y crítica a Bourdieu, propone una lectura contemporánea de la socialización, acuñando la expresión hombre plural.

Palabras claves: hecho social total; habitus; hombre plural.

Alceu Ravanello Ferraro

Liberalismos e educação. Ou por que o Brasil não podia ir além de Mandeville

Este trabalho examina três autores que expressam versões típicas do liberalismo europeu do século XVIII: o liberalismo de Mandeville, que teme a instrução do povo; o liberalismo de Smith, o qual requer uma instrução mínima (ler, escrever e contar) para todos os trabalhadores; e o liberalismo de Condorcet, que defende uma educação comum, universal, pública, gratuita e obrigatória. Fundamentado no princípio da igualdade de todos os seres humanos, Condorcet contrapõese a Mandeville e avança para além de Smith, que fundamentam suas posições apenas no princípio da liberdade. A opção apoiou-se no pressuposto de que o confronto estabelecido entre eles poderia constituir-se em referência para o entendimento do tipo de liberalismo que vingou no Brasil Império, em especial no momento da reforma eleitoral de 1881, a qual, ao introduzir a eleição direta, determinou a exclusão dos analfabetos do direito de voto, mas é referência também para o entendimento do que se passa hoje no País.

Palavras-chave: liberalismo; Brasil; alfabetização; escolarização.

Liberalisms and education, or why Brazil could not go beyond Mandeville

This paper discusses three authors who express three typical versions 